Article

\title{
Beyond the Sendai Framework for Disaster Risk Reduction: Vulnerability Reduction as a Challenge Involving Historical and Traditional Buildings
}

\author{
Valentina Pica \\ Marie Sklodowska-Curie Fellow, Department of Architecture, Roma Tre University, 00155 Rome, Italy; \\ valentina.pica@uniroma3.it
}

Received: 9 December 2017; Accepted: 19 March 2018; Published: 27 March 2018

\begin{abstract}
In observance of the international procedures on disaster risk management, and in particular the Sendai Framework (2015), this research focuses on how more specific procedures related to it can be made effective in the treatment of historic areas worldwide. Disaster risk management is now viewed as being important in the context of historic buildings, as they are strongly related to cultural identity as well as to resilient communities, and can have a large impact on local economies. The study points out that cultural heritage might be the core field of action for capacity building in less vulnerable places, and that its protection is one of the main tasks to attend to in order to achieve the goal of vulnerability reduction. The paper also aims to answer questions such as: which actions could allow better protection of cultural heritage? Is it correct to involve local communities in reconstruction plans by capacity building and self-managed projects? How have reconstruction plans been managed recently worldwide? By further developing the applicability of the priority areas of action of the Sendai Framework, the research illustrates critical points and best practices that will hopefully support disaster risk reduction based on strategic management and remote monitoring, involving technologies and social participation.
\end{abstract}

Keywords: disaster risk management and reduction; protocols; governance; conservation; masterplans; housing reconstruction

\section{Introduction}

Reducing local vulnerability is the main and still unattended challenge that can make a difference in the immediate aftermath of a disaster, but also beforehand by preventing damage. This challenge has grown critical due to increasing climate change [1], natural and man-made disasters, together with rapid urbanization (called urban sprawl [2]). These factors are also associated with the transformation of peripheral areas around cities worldwide, often with very poor construction quality. Depopulation of marginal rural settings, where historic centers of high cultural value are frequently situated, is another of the consequences of disasters, which leads to the general lack of local policies of recovery. Nowadays, situations of protracted crisis and a relapse back into conflict are becoming more frequent. As a result, opportunities for swift recovery of the cultural sector are significantly reduced, leading in turn to further irreversible loss and vulnerability.

There is today growing recognition that the protection of cultural diversity and the promotion of cultural pluralism, by safeguarding the tangible and intangible heritage of communities and the protection of human rights and fundamental freedoms, is more than a cultural emergency. It is a security and humanitarian imperative in conflict and transition situations, and an essential element in ensuring sustainable peace and development. It is also crucial as regards risk management because of, a lack of maintenance, among other factors. 
In Italy, built minor heritage recovery is very challenging and urgent, has it has been estimated that 70\% of domestic buildings were built before 1976 [3] (Figure 1) or are historic and in a mediocre condition. The seismic retrofitting of built heritage is far from occupying a large share of the construction market [4].
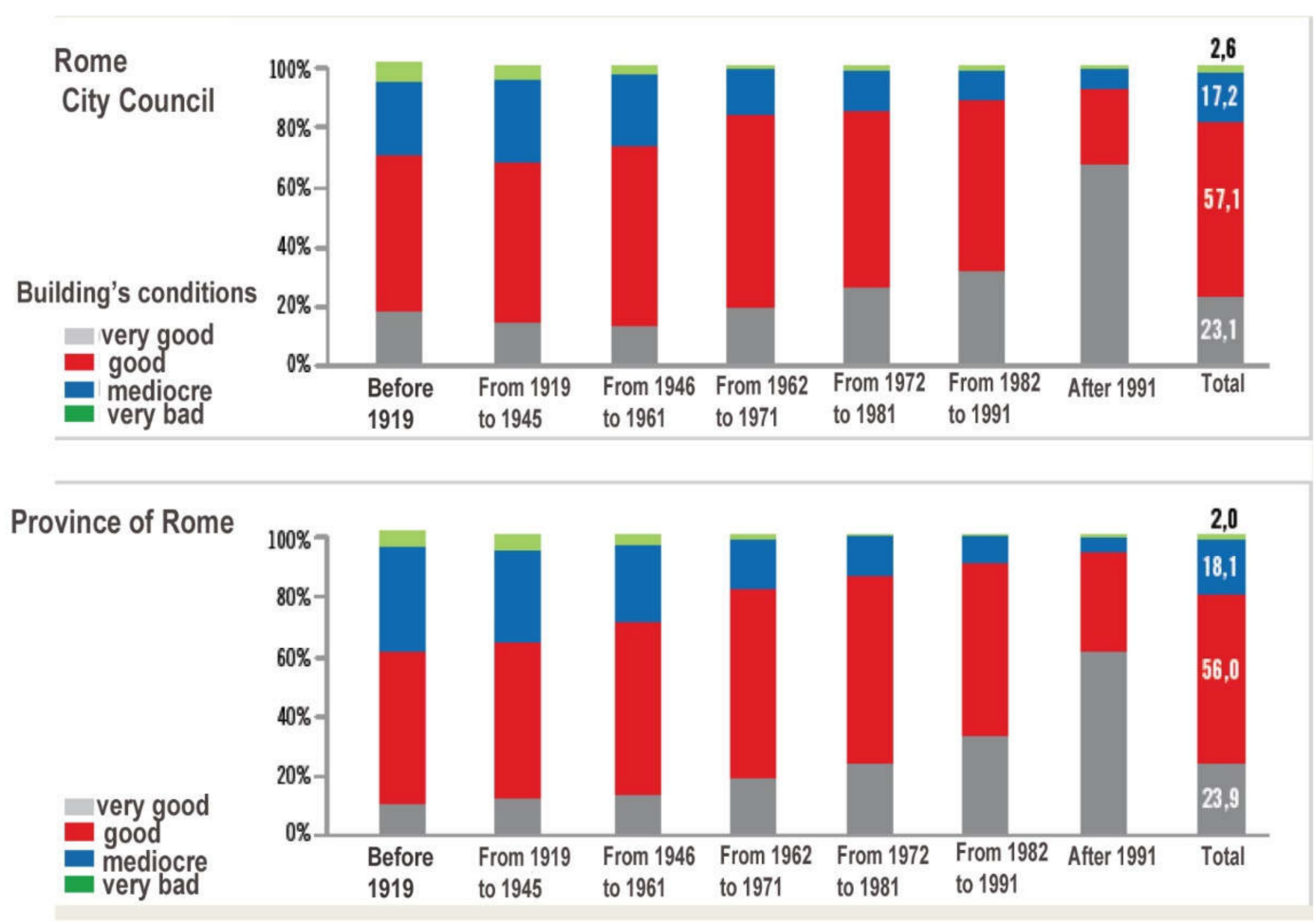

Figure 1. Ages of construction of the buildings in the city of Rome and its province, Italy. Source: CRESME.

Historic and vernacular architecture is the resilient product of communities grounded on traditions that have built a cultural identity and social cohesion [5]. Participation and access to culture and its living expressions, including intangible heritage, can help strengthen people's resilience and sustain their efforts to live through and overcome crisis [6].

Nonetheless, very little is being done by regional governments, especially regarding built heritage, due to the economic crisis and the lack of specific integrated urban strategies and regulatory instruments [7]. However, in 2015 the United Nations Educational, Scientific and Cultural Organization (UNESCO) launched a campaign, called Unite4Heritage, aimed at protecting and safeguarding heritage and cultural pluralism from conflict destruction. A programmatic document connected to the initiative was also released [8].

\section{The Sendai Framework for Disaster Risk Reduction: Towards the Implementation of Disaster Risk Management across the World}

Concerning risk management, United Nations member states have recently formulated The Sendai Framework for Disaster Risk Reduction, a 15-year, voluntary, non-binding agreement which recognizes that the state has the primary role in reducing disaster risk but that responsibility should be shared with other stakeholders including local government, the private sector and other stakeholders. This contains explicit guidelines in order to enhance a government's policies for disaster risk management and reduction by improving prevention as well as by reducing local vulnerability. The document is of great interest also because it draws the attention of national and worldwide policies to the relations between cultural heritage protection and territorial resilience. It was written by the ministers from 187 UN member states gathered at the Third United Nations Conference on Disaster Risk Reduction (held in 
Sendai in 2015) with the objective of implementing the Yogo Framework for Action (HFA) 2005-2015. The conference aimed to disseminate the framework across the world and laid the groundwork for an international shift from disaster response management (which has been made effective recently, but just in most developed countries) to risk vulnerability prevention through a people-centered approach in order to strengthen communities' resilience, a genuine challenge for the future, even in Western, developed countries.

Through a research methodology based on a comparative analysis of the items contained in the framework and of the scientific literature on risk management for cultural heritage, as well as on the study of the main recent institutional and collective initiatives, we present new scenarios in order to deepen the practical implications of the general Sendai Framework as far as cultural heritage and resilience is concerned. Part of the present research was carried out during a post-doctoral internship within the Department of Disaster Risk Management at the International Centre for the Study of the Preservation and Restoration of Cultural Property (ICCROM), where the author could work on a general analysis of the contents of the framework and its gaps according to cultural heritage conservation and protection standards.

To summarize, the present research aims to point out how governance (policies, legislation and organizational arrangements) and local initiatives (e.g., involving municipalities) targeted at addressing the severity of disasters could be implemented under the influence of the Sendai Framework. These could be more effective at reducing disaster emergencies and protecting cultural heritage (both tangible and intangible, as well as movable and unmovable) more effectively. The paper has a special focus on built heritage.

To achieve these goals, we start by analysing briefly the framework, and its relationship with cultural heritage. The document's statements have been oriented at four specific priority areas of political, social, cultural and economic plans of intervention, which are:

- "Priority 1: Understanding disaster risk". In order to raise awareness on risk and vulnerability among the community members and the stakeholders.

- "Priority 2: Strengthening disaster risk governance to manage disaster risk".

- "Priority 3: Investing in disaster risk reduction for resilience".

- "Priority 4: Enhancing disaster preparedness for effective response and to Build Back Better in recovery, rehabilitation and reconstruction".

Targeted measures within and across these fields of action for disaster risk reduction should be promoted by states at international, national local, and regional levels.

Cultural heritage is only mentioned in this groundwork document as follows:

In the third paragraph, where the guiding principles of the framework are introduced, point (c) of the text includes the protection of cultural assets:

“(c) Managing the risk of disasters is aimed at protecting persons and their property, health, livelihoods and productive assets, as well as cultural and environmental assets, while promoting and protecting all human rights, including the right to development".

In Priority Area 1, point (d), the framework states:

“(d) To systematically evaluate, record, share and publicly account for disaster losses and understand the economic, social, health, education, environmental and cultural heritage impacts, as appropriate, in the context of event-specific hazard-exposure and vulnerability information".

In Priority Area 3, point (d) declares that in order to achieve effective public and private investments in disaster risk prevention and reduction for resilience, it is important:

"To protect or support the protection of cultural and collecting institutions and other sites of historical, cultural heritage and religious interest". 
It should be noted that the attention paid by these undoubtedly crucial guidelines to cultural heritage as well as to historic buildings must be further developed.

In the 10 years following the adoption of the Hyogo Framework for Action (2005), the previous groundwork to the Sendai Framework, we have witnessed an acceleration in the formulation and implementation of policies and measures whose goals envisage reducing the risk related to natural hazards (phenomena or events). These policies are frequently complemented with multiple actions that include awareness-raising campaigns, risk assessments, early warning systems, emergency response capacities, and so on. At national and local levels, most countries, have developed legislation, policies, programs and projects to address the increasing disaster risk threat to humanity.

The most serious aspect of the threat is the rapid increase in exposure and vulnerability of populations, particularly those in urban areas, to natural events, which themselves are increasing but at a much lower rate. Hence, the need observed in the framework to address the disaster risk issue with terms other than "natural disasters". The concept behind this shift in terminology is that the phrase "natural disasters" conveys the perception that if disasters are natural there is little that can be done, except by preparing to respond to them, instead of reducing vulnerability and building resilience, which need to be the focus of risk reduction and management policies.

Nonetheless, from an initial observation it emerges that a new approach is urgently required at both international and national levels to operationalize the link between protection of cultural heritage (including traditional and vernacular architecture), social equity and diversity on the one hand and humanitarian actions, peace-building processes and security policies on the other hand [9]. Given the crucial importance of the Sendai Framework, cultural heritage protection should be included in more detailed plans of action, or in operative protocols, specifically focused on measures and strategies targeted at its promotion and loss prevention in the aftermath of a disaster.

Next, a brief analysis has been drafted on how the priority actions of the Sendai Framework could be enhanced, as well as on how they have been and are addressed worldwide today. Also, a final paragraph showing some critical aspects and goals achieved has been introduced, with the purpose of making a contribution focused on providing institutional and collective initiatives and procedures that, if well oriented, could result in effective improvements.

\section{How Cultural Heritage Protection Can be Made Effective while Reducing Local Vulnerability: The Case of Italy}

To lay the basis for more detailed guidelines, we have analysed best practices following the four priority criteria of the Sendai Framework. This section briefly describes the actions related to the first two priority areas. They could be of useful reference to understand how to better protect cultural heritage from disaster, and in which ways these procedures could be included into specific political tools such as protocols.

Italy has a longstanding tradition of cultural heritage protection and large influence worldwide, and has recently been trying to link sustainable development to urban recovery strategies and cultural heritage management. The most challenging aspects Italy faces in order to achieve both resilience and cultural heritage protection are, according to Italian experts, related to risk awareness and governance procedures, both issues included into the Sendai Framework, which must be further developed [10].

These first two steps would lead the last two categories of action, by enhancing communities and governments to find new funding or by acquiring tools to save resources in order to carry out more effective recovery masterplans.

Regarding the priority sector of action n.1 of this document, several measures such as social innovative events should be adopted or financed by local governments in order to educate on risk prevention and awareness, as well as to disseminate the issues related to cultural heritage protection from disasters and the reduction of vulnerability of museums and other cultural sites. 


\subsection{Tools to Enhance Risk Awareness}

One effective action could be enhancing Walkabout Events (like those promoted by the Italian Urban Experience association [11]): a social and cultural tool with a cross-sectoral approach to empower communities, allowing the sharing of indigenous local practices while educating people to risk awareness and realizing social inclusion between citizens from different countries, of different ages and genders. These involve making them walk together across the urban or rural built contexts, before and also after a disaster, in order to register open data grabbed in a site map and a web-radio. The post-event work could be coordinated and done by volunteers in order to share information about risk reduction as well as local cultural heritage protection and post-disaster activities aimed at strengthening the community's resilience.

Another procedure to raise risk awareness could be organizing open talks, civic talks, world cafés [12] in municipal open spaces (libraries, show-rooms, etc.) or cultural spaces (bookshops, stores, etc.). These tools are used within different movements and social platforms for innovative and creative problem-solving processes related to resilience and economical and climatic global change, and should be better targeted at informing about the importance of heritage protection and recovery in post-disaster communities for their revitalization, as well as at other topics such as: governance measures through bottom-up processes [13], real cases of reconstruction and cultural heritage protection, and real stories of private involvement, etc. In Italy they have been used in several socially innovative events on the topics of bottom-up urban regeneration and resilience, like those set up by the local associations (e.g., at Altamura, in the Italian region of Puglia) [14].

These social tools can be useful also for addressing the specific goals of the second priority area of the Sendai Framework, as they can play a decisive role in the governance and design of effective programs or protocols through social participation. These events can provide to promoters and cultural heritage institutions local data supporting a networking team that listens directly to the real needs of the citizens, in order to think about cheap solutions, tailored to concrete problems, without wasting money on less-effective work. This factor could be of great impact on the economical aspect of financing risk management and reduction plans, by accepting private stakeholders' proposals and involving them in planning. The institutions will also have the responsibility and the merit of creating a conscious, informed community, more prepared for uncertainty and with more awareness of the criticalities of their territory. Moreover, these meetings could enhance the involvement of private investors in the plans at national, regional and local levels.

As for education, enhancing first aid in historical contexts in the training of students could be effective. This training could host experts from intergovernmental institutions such as the ICCROM (International Centre for the Study of the Preservation and Restoration of Cultural Property), or from universities. Operative groups of volunteers could also be involved in training students. The ICCROM Disaster Risk Management department is based in Rome and is offering these kind of training courses across the world, but could enhance its offer throughout Italy and Europe with new funding aimed at reaching the goal of scholar education. Each course basically would train students to learn how not to cause further damage to any collection's object or damaged building after the disaster while trying to preserve cultural heritage.

\subsection{Tools to Strengthen Disaster Risk Governance}

Regarding the priority field of action n.2, enhancing central and regional governance can be related to strategic protocols for risk management and sustainable development, according to the Policy Document for the Integration of a Sustainable Development Perspective into the Processes of the World Heritage Convention, as adopted by the General Assembly of States Parties to the World Heritage Convention at its 20th session (UNESCO, 2015). These strategic protocols could guide decision-making processes at a territorial level and be targeted at local authorities such as city councils. They would be effective tools for responding to the lack of specific legislation, or local administrative 
actions by filling gaps, especially in developed regions like Europe, which has some of the most beautiful and fragile historic cities in the world.

A research project on designing a protocol of integrated interventions for the revitalization of small historic centers of Italy and Spain threatened by depopulation and other kind of risk (environmental and seismic, moreover), is being carried out through a Horizon 2020 postdoctoral fellowship by the author [15]. A protocol like this could be implemented in order to be included in a management plan, which is a document specifying in detail all the actions and tools for heritage protection. At the same time, this would respond to the needs of contemporary life. It should contain economic incentives, legislative, financial, administrative and conservation documents, as well as conservation and monitoring plans.

Formulating these kinds of protocols requires an integrated approach connecting research, education, policy-making and different disciplines. These tools should guarantee good assessments of the impacts of disasters on tangible and intangible cultural heritage, and they should be grounded on a baseline consisting of SWOT analysis and cataloguing.

Originated by Albert S. Humphrey in the 1960s, the SWOT matrix is a strategic planning tool used to evaluate the Strengths, Weaknesses, Opportunities and Threats of a project or a company or any other situation where an organization or an individual has to make a decision to achieve a goal; the tool is useful for uncovering opportunities that a business company, a city council or a team are well-placed to exploit. By understanding the weaknesses of their business, it is effective to manage and eliminate threats that would otherwise catch them unawares (Figure 2).

\section{SWOT ANALYSIS}

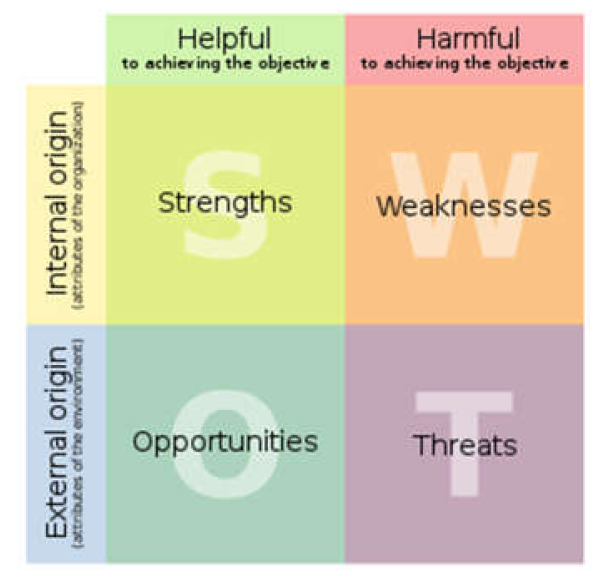

Figure 2. Illustrative diagram of a SWOT (strengths, weaknesses, opportunities, and threats) matrix.

The operative procedures of these strategic protocols might be supported by multimedia platforms targeted at social participation, according to the recent model of the sustainable smart city [16]. A best practice in Italy is that of "Iperbole civic net" of the City Council of Bologna, a community network with forums for participated projects and proposals for the reuse of buildings, abandonment and degradation being among the main factors of risk [17]. The tool used as a baseline to enhance this activity is the "Regulation on Urban Commons", which is now available for all city councils and helps to define in a structured way, in line with the one approved in 2014 by the City of Bologna, many innovative experiences carried out and hence enables the relationship between active citizens and administration, thanks to the introduction of the "Pact of Collaboration". The pact of collaboration is the tool used by the city council and active citizens to reach agreements on everything needed for the implementation of care, shared management and regeneration of an urban common good. These pacts are a powerful tool to trigger widespread civic sensitivity and to foster the idea of a change in the 
type of relation between residents and the local authority. With this new tool, active citizens (informal groups, associations, non-governmental organizations (NGOs), ... ) can sign a pact with the city that regulates designing, management and monitoring of the interventions. This is possible through two different types of procedures:

- Public consultation.

The city can identify urban common on which it will be possible to activate a pact of collaboration. Upon approval of the guidelines, the city publishes a public call for proposal.

- Collaboration proposals submitted by active citizens.

Anyone can make a proposal for the care, shared management or regeneration of an urban common good: associations, cooperatives, businesses, formal or informal groups active in the urban area.

Nonetheless, starting from this work, it would be important to further enable the integration of useful services among citizens and visitors with the subject of risk assessment and mitigation through monitoring operations and initiatives supporting not only the emergency response, but also risk reduction and prevention. This kind of platform would also contribute to informing people about cultural heritage collections and other cultural issues, such as the accessibility of sites, mobility and recreation or refreshment in the city.

Including in the platform a database containing the catalogue of historic buildings present, the site's conservation status and the risk assessment carried out, it would be possible to link the authorities and experts responsible for emergency management with such information. In addition, geo-referencing these data and those that can be acquired through remote monitoring at a remote level, employees will have a real-time alert at the moment of the alarm and a series of decisive news updates for their effective intervention, in the form of maps continuously updated with indications of affected buildings and points of cultural interest. Similar services could be made available to citizens and visitors by accessing the platform from mobile devices and providing them with information on the actions to be taken if required. However, the potential of such a system is not limited to the scope of the emergency: it represents a frontier for improving knowledge of cultural sites and city services.

Given that the idea of "preventive conservation" is today the primary focus of cultural preservation worldwide, specific protocols for prevention and disaster damage reduction of cultural heritage are necessary, based on multifactorial assessments and multidisciplinary methods, and consisting of useful guidelines that could be shared and applied in the plans of different institutions, such as museums, local authorities, non-profit organizations, and so on. These protocols would be based on tools of technical measurement and monitoring as well as of programmed protection.

Although risks identification and monitoring methods are well-known practices, often their computer-based assessment methodologies are not yet sufficiently developed [18].

A similar problem is occurring at an urban scale, for which there are no indicators of global use to evaluate the impact of cultural heritage on sustainable development and disaster risk management [19].

Several research projects are being carrying out at the moment on these topics and concerning the environment, in the hope that institutions will further develop them and ventually turn their goals into operative protocols [20].

Regarding built heritage, they would be used by city councils and work through databases included in risk maps of the sites, with a classification of the levels of risk (e.g., seismic), in order to prioritize the different kinds of preventive intervention and to reduce the damage that can be visited upon cultural heritage and on buildings during safety and security operations [21].

First, general procedures would define the site maps and, therefore, they could be implemented with new data proceeding also from local users through information technology applications on mobile phones, for instance. This would be connected to the previously described strategic platforms targeted at the engagement of the local community of citizens, politicians and investors in the management and decision-making processes, and could also help data interoperability. 
Risk-mitigation plans should also take into account both natural and man-made factors so as to act in such a way as to limit the risk coefficient assigned to them, compatible with the needs of urban life.

Summarizing the main findings, these indicate:

- Designing an operative protocol for emergency prevention and response within an historic city should follow an integrated approach between participated urban planning, smart city measures, cultural heritage recovery and protection, and several other disciplines. Within this framework, "Smart Heritage" is part of sustainable development.

- This might include a platform with georeferenced maps indicating void buildings in order to enhance their reuse; it also might indicate early recording of damage (a kind of online observatory) as well as identify escape routes and access by rescue vehicles in roads that need to be kept free of cars and objects of any kind. It should define as well security areas, collection points, and the roles of the agents in charge of the security of people and of cultural heritage elements.

- These operative tools should be grounded on an accurate analysis of the site, carried out through social participation and social tools, together with the SWOT analysis. They would be made operative by enhancing an automatic early-warning system integrating multiple sensors to remotely monitor areas of archaeological and cultural interest for the risk of fire, for instance, and extreme weather conditions.

- This kind of system should integrate various detectors including optical cameras, infrared cameras at different wavebands, passive infrared (PIR) sensors, a wireless sensor network of temperature and humidity sensors, and local weather stations on the deployment sites. The signals and measurements collected from these sensors are transmitted to the control centre, which employs intelligent computer vision and pattern-recognition algorithms as well as data-fusion techniques to automatically analyse and combine sensor information and detect the presence of fire or smoke.

- A remotely controlled monitoring system, at the same time as safeguarding cultural heritage and risk mitigation, would be able to alert in real-time the organizations responsible for the protection and management of an emergency in case of fire, for instance [22].

\section{How Investing on Disaster Risk Management and Responding to Emergency Can be Improved}

Concerning the priority area n.3 of the Sendai Framework, it has been observed that very little effort and insufficient funds have been devoted worldwide to the reduction of social vulnerabilities, which are the main cause of the heavy and negative impacts of natural hazards on cultural heritage.

Risk assessments and early-warning systems at the moment are tools mostly utilized to identify and prepare for natural hazards rather than to assess and reduce social vulnerability or build resilience. Moreover, for many developing countries, financing disaster risk reduction plans is a huge effort. Finally, special funds should be allocated to poverty eradication, providing people with jobs working for cultural heritage protection, conservation and security before and after a disaster. Moreover, maintenance of traditional capabilities should be encouraged. These capabilities might be related to farming, self-reliance and security from emergencies. The employment of ground-rooted women should be guaranteed, as well as of elderly people and unemployed adults requiring training, and for traditional heritage's repair, maintenance, conservation or retrofitting.

Multimedia platforms, introduced in the previous section, could also enhance crowdfunding campaigns, which would empower disaster risk management-dedicated institutions, humanitarian agencies, cultural heritage institutions, NGOs, non-profit associations and any other kind of organizations or group of citizens committed to disaster risk reduction and cultural heritage protection.

Employing trained volunteers in case of an emergency response could be of great support. These should be trained people, able to stabilize, secure, document and package cultural heritage elements. This factor is useful in order to reduce waste and save money. Within special protocols for 
cultural first aiders, or in the national plans, there should be specific measures on how these volunteers could be employed and for what kind of tasks.

\section{Measures to Enhance Effective Response for Cultural Heritage Protection}

Concerning the priority area n.4., taking into account the understanding of cultural inheritance across civilisations which is embodied in the Nara Document of 1994 (Nara Document on Authenticity), it is now apparent that recovery from destruction cannot be understood as a single undertaking or programme, but involves processes and long-term commitments in which local populations, authorities and international bodies exercise critical roles [23].

First of all, providing an effective first aid response is crucial. In the event of disaster, working relationships and communication networks need to function effectively where normal communications may be compromised. This is a necessary phase for rebuilding better, stabilizing and securing the damaged structures, and recovering collections (Figure 3).

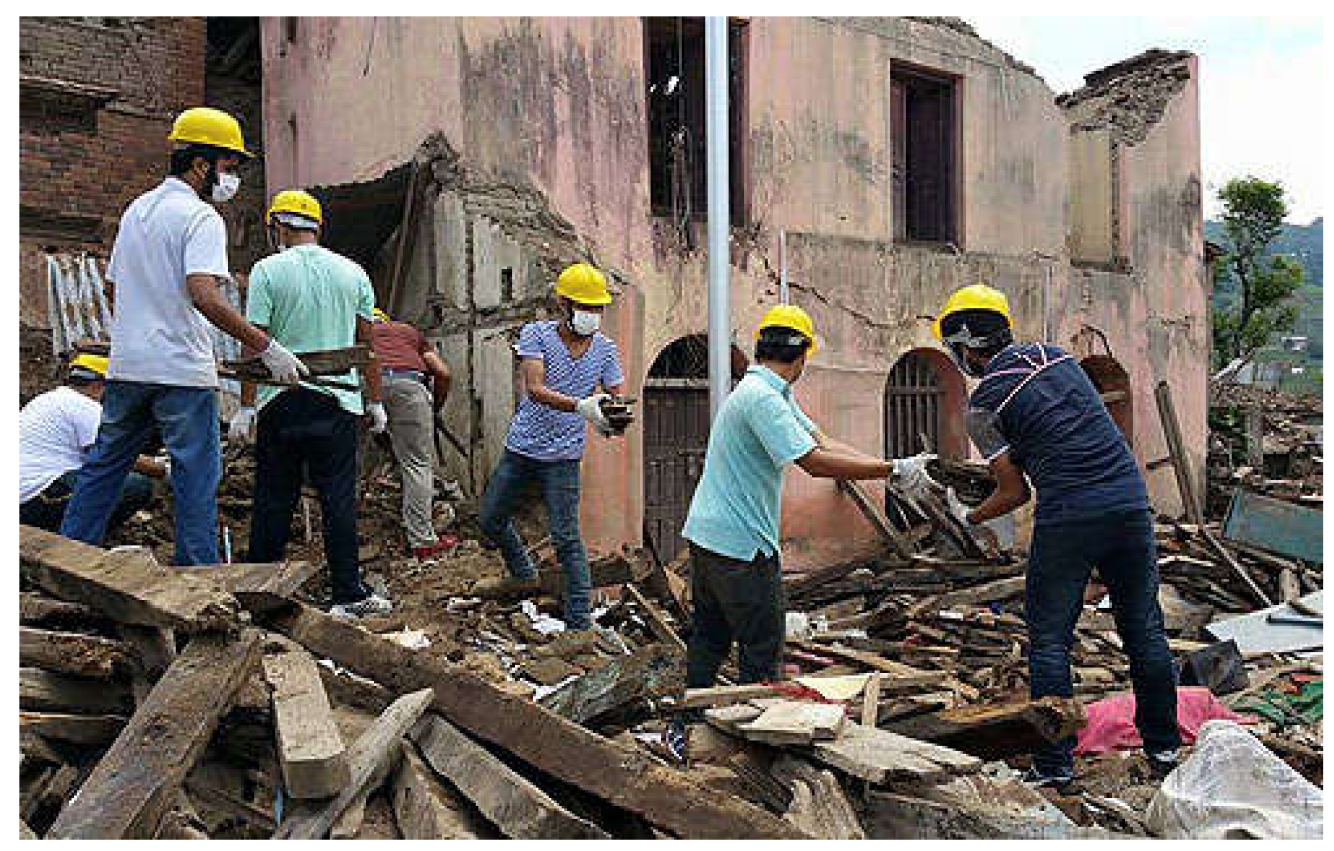

Figure 3. Operations of salvage of the mural painting fragments at Shantipur guided by the International Centre for the Study of the Preservation and Restoration of Cultural Property (ICCROM) experts and other international partners in the aftermath of the earthquake in Nepal, 2015.

Next, adopting participatory approaches to "Build Back Better" is also important, but before this, surveying and documentation are crucial.

Due to the drawbacks of a contractor-driven approach toward housing reconstruction, governments, international finance institutions, and humanitarian agencies need to consider alternatives [24]. Within the framework of several reconstruction programs in Asia and Latin America, a growing number of NGOs have adopted participatory approaches that appear to be more cost-effective and empowering than contractor-driven reconstruction (e.g., Ocotal in Nicaragua and Gujarat in India, analysed in the next section).

Under this approach, the agency plays a leading role in construction, but the role of the community is variable. The role given to participation varies significantly from case to case. Communities may be involved in the decision-making process throughout the project, including house design and the selection of construction materials. However, their role may be limited to the provision of unpaid labour or to a swift consultation of community leaders [25]. 
Encouraging the active participation of disaster-affected communities in construction may be an effective strategy for restoring confidence among people who have gone through the traumatic experience of a disaster.

Finally, the development of a master plan for the maintenance and recovery of cultural heritage might be carried out. This plan would be based on the specific protocols for prevention (introduced in the previous section) and operating procedures for first cultural aid as well as on the multimedia platforms for monitoring. Additionally, it should involve a focus on the attributes that convey Outstanding Universal Value to the World Heritage that has been damaged or is at risk [23]. Moreover, it is expected that the Sendai framework may have wider application to assisting damaged heritage places and identifying a wide spectrum of possibilities for the future using the Universal Design for new buildings.

This type of design is intended to reflect the interests of the entire community, particularly people with disabilities along with the elderly and the infirm. Its principles include equitable use, i.e., accessibility for people of diverse abilities; flexibility to accommodate a wide range of individual preferences; simple and intuitive usability; perceptible information; tolerance for error so as to minimize the adverse effects of accidents or unintended use; low physical effort so that people of differing strengths can all use the structure; and enough size and space to accommodate everyone's approach and use.

Once the recovery option has been agreed with the local community or in principle, it can become the basis for a specific programme of actions directed towards maintenance and recovery. The master plan should incorporate detailed project plans (action plans) together with implementation measures, risk assessment and timescales (based, for instance, on the Gantt chart, a type of bar chart, that illustrates a project schedule).

This plan should be created through a process involving relevant stakeholders in consultation with advisory bodies and the World Heritage Centre. Action plan implementation measures should be reported at agreed stages in the process. The plan should include effective response, which depends on inclusivity. The displaced, including the diaspora of the heritage practitioners, should be given special consideration.

During a protracted crisis, the relationship between a cultural heritage place and its community is often disrupted, sometimes for years.

The possible reconstruction depends on maintaining some sort of relationship alive in the minds of the displaced, including the younger generations. This should be part of an overall strategy for cultural recovery. This factor would be applied at local and national levels and would include essential international liaison. The plan should also ensure that all housing and new schools will be $100 \%$ safe and that they can face disasters that might befall the communities in which they are located.

In summary, relating to the third and fourth priority actions of the Sendai Framework, the following main findings can be emphasized:

- economic management not only deals with public financing, fundraising and donations, but can also be supported by involving local volunteers and non-profit associations;

- it is important to set up educative events on traditional jobs, in order to recover and maintain cultural know-how as well as to empower fragile social classes; it is also crucial to create capacity building in the communities in order to reduce waste (due to the payment of expert laborers) and enhance their cohesion and resilience;

- national plans should include specific operating procedures for cultural first aiders, which should be adopted by various local institutions;

- the correct assessment (surveying, documentation, stabilization, secureness) of a disaster in its aftermath is crucial, and specialized professionals within the various institutions should do this, in order to support first aiders or governmental forces (i.e., architects and engineers working in museums, schools, universities, etc.);

- participatory projects have been demonstrated to be more effective than contractor-driven approaches to reconstruction, even if central coordination is crucial; 
- national masterplans supported by multimedia platforms with georeferenced contents as well as with remote monitoring and valuation of actions and climatic changes are mainly absent, even in developed countries, and should be developed and coordinated by local governments. It is crucial to guide appropriately decision-making processes and governance.

- These masterplans should be grounded on social participation and a Universal Design approach as well as on public-private partnerships in order to enhance social equity and local stakeholders' involvement.

\section{How Disaster Risk Management of Cultural Heritage has been Addressed Recently in Different Countries (Nine from Five Continents)}

We have mostly analysed the countries with conflicts and with an important built heritage at risk of: Syria and Iraq, in Arab States; Myanmar, Japan and India in Asia; Nicaragua and Chile in Latin America; The Balkans and Italy in Europe; the last of these most of all because of the recent earthquakes.

Regarding the first priority area of the Sendai Framework, several training initiatives have been undertaken and some reports and official statements have been published to document the dramatic situation in Syria, Iraq, as well as in other regions of Middle East and in the other analysed countries.

As far as the other priority areas of the Framework, policies and governmental actions are weaker, although there have been some efforts.

\subsection{Activities to Enhance Risk Awareness for Cultural Heritage in the Analysed Countries}

In January 2013, the International Council on Monuments and Sites (ICOMOS) in cooperation with ICCROM, the DGAM (Directorate General of Antiquities and Museums in Syria) and UNESCO managed to hold an e-learning course for Syrian cultural heritage professionals, conducted by ICORP, the ICOMOS International Scientific Committee on Risk Preparedness [26]. It was coordinated by the ICOMOS permanent and operational working group on Syria, established informally as early as in 2012. Since 2014, and also in charge of Iraq, the working group was validated by resolution of the General Assembly in Florence in November 2014 as the ICOMOS Working Group for Safeguarding Cultural Heritage in Syria and Iraq. Moreover, in order to carry on efforts to provide support to cultural heritage professionals in Syria, the ICCROM-ATHAR (Architectural and Archaeological Tangible Heritage in the Arab Region) Regional Centre recently joined forces with UNESCO and the ARC-WH (Arab Regional Centre for World Heritage-Bahrain) to hold a course for Syrian professionals in Beirut, Lebanon, on First Aid to Built Cultural Heritage, in 2015.

The aim was to establish national teams capable of undertaking emergency response interventions to secure endangered built cultural heritage, and train other colleagues in the country. Twenty-three professionals working in Aleppo, Damascus, Daraa, Idleb, Deir Al-Zor and Homs participated in this intensive course. Participants discussed several aspects relevant to emergency response to endangered heritage: risk assessment, damage assessment, first aid to cultural heritage, rapid documentation, community engagement and emergency consolidation of damaged monuments and sites. The training is the follow-up to a workshop organized in late 2014, which was attended by nine of the participants in this year's course. International and Syrian experts from UNESCO, ICCROM, ICOMOS and local NGOs conducted this workshop's programme that was developed in close cooperation with the DGAM in Syria.

The ICOMOS World Report 2011-2013 documented the huge loss of cultural heritage collections and historic buildings in Syria during the civil war in order to enhance the dissemination of the necessary amount of actions to recover this and better understand the level of damage and the high risk that the existing cultural heritage elements still face every day.

First aid heritage training was organized in 2015 in Iraq in partnership with the University of Pennsylvania, the Smithsonian Institution and ICCROM, the Cultural Emergency Response programme (CER), and this was called 'Cultural Heritage, Disaster Preparedness and Emergency Training'. The course was led by the Iraqi Institute for the Conservation of Antiquities and Heritage 
(IICAH), and trained 17 local heritage professionals for a period of four weeks, and was the first of its kind in Iraq. The 'Cultural Heritage, Disaster Preparedness and Emergency Training' was designed to assist Iraqi professionals in preparing for continued heritage destruction as well as planning for a response once the conflict ends. The group of participants, which included archaeologists, museum personnel, heritage engineers and architects, were selected by the State Board of Antiquities and Heritage of Iraq (SBAH) in Baghdad and the Kurdistan Regional Government in Erbil. Taught by the IICAH, the course educated the heritage professionals on how to prepare irreplaceable cultural heritage sites and collections for safekeeping in anticipation of possible conflict. Moreover, the students learned how to respond to post-conflict emergencies by documenting damage and stabilising materials at risk. A range of topics was addressed, such as: basic inventory procedures, safe packing and movement of collections, damage assessment and documentation, and recovery plans for heritage sites and museums.

Another kind of initiative to disseminate risk awareness on subject of the Middle East was given by the University of Pennsylvania Museum of Archaeology and Anthropology at the conference "The Future of the Past, From Amphipolis to Mosul" from 10-11 April 2015, which was organized to engage scholars in an intellectual dialogue, encouraging future cultural heritage practitioners from different disciplines to endorse new approaches and technologies to cultural heritage preservation in their respective fields. They were particularly interested in exploring the eastern Mediterranean, including Greece, Turkey, the Middle East, and northern Africa. The conference was prompted also by a number of similar events in the United States and abroad, advocating a more active role for heritage professionals who, in the light of the recent developments in the Middle East, are facing something of an identity crisis. Since the conference taken in April 2015, numerous academic and other non-profit institutions have responded to the urgent call to act fast. The conference "Erasing the Past: Da'esh and the Crisis of Antiquities Destruction" at Wellesley College in September 2015, the workshop "Evidence and Emergency Responses to Cultural Heritage Destruction in the Middle East" at the 2016 Archaeological Institute of America Annual Meeting, and the recent symposium "Beyond Destruction: Archaeology and Cultural Heritage" at the University of California, Berkeley, are just a few of the initiatives that responded to that dissemination activity.

The attacks against Nimrud in March 2015 and the ongoing damage to the archaeological site by terrorists were denounced in a UNESCO press release of April 2015 by Director-General Irina Bokova, declaring that the "deliberate destruction of heritage is a war crime". Unfortunately, no report on the situation is available. The report on the future of the heritage of Mosul after the destruction by ISIS (Islamic State) in April 2014 clearly points out the importance of research and documentation for possible post-disaster reconstruction.

In the case of Yemen, again there is no report to describe the extent of cultural heritage at risk due to the ongoing armed conflict, but ICOMOS in a statement of 23 April 2015 expressed its deep concern about threats to cultural properties in Yemen, mentioning the three Cultural World Heritage Sites, but also many other places of great cultural importance. On 3 June 2015 the International Committee of the Blue Shield published a statement on extremely worrying reports about the destruction of cultural properties, including the bombing of the World Heritage Site of the Old City of Sana'a, (Figure 4) and urged all parties to abide by the terms of the 1954 Hague Convention [27].

It is worth mentioning that for the first time ICLAFI, the ICOMOS Legal International Scientific Committee, is contributing to an edition of the series ICOMOS World Report (Heritage at Risk or H@R) with a very detailed report related to the legal problems in connection with the protection of cultural properties in the event of armed conflicts, followed by a recommendation to expand the definition of cultural heritage in Heritage at Risk.

In the continent of Asia, on the subject of enhancing initiatives within the first priority sector of action of the Sendai Framework, recently various conferences and training sessions have been hosted in Japan, Myanmar and India, and various important publications have been made available to the public on disaster and risk reduction awareness. 


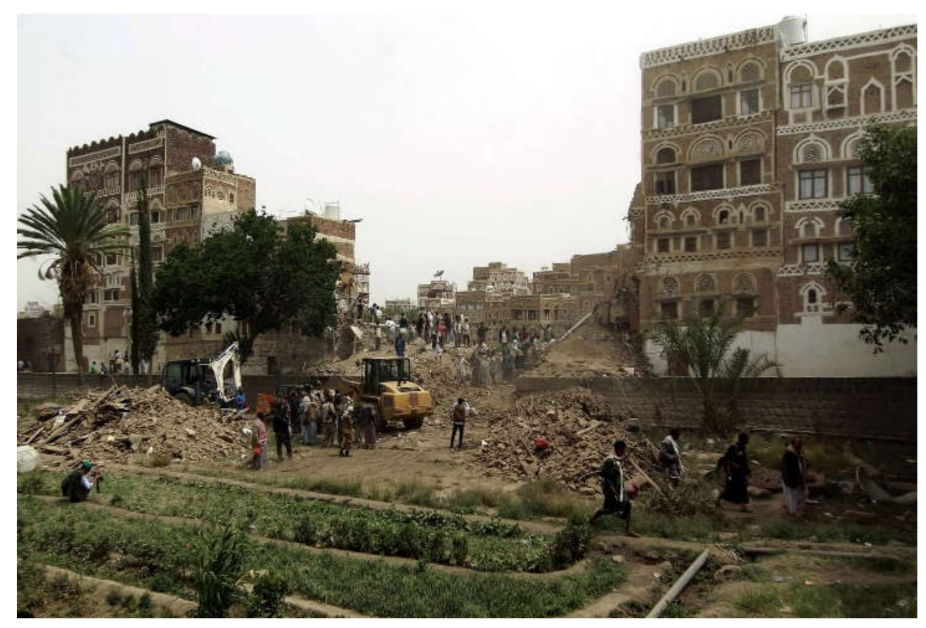

Figure 4. Buildings of in the Old City of Sana'a in the aftermath of the air strike of June 2015. Photograph: Mohammed Huwais/AFP/Getty Images.

The World Conference on Disaster Reduction (WCDR), a specialist meeting on cultural heritage risk management hosted in Japan since 2005, laid the basis of the 'International training course on disaster risk management of cultural heritage' held in various forms since then in Kyoto, Kobe and Sasayama.

In response to the recommendations of this meeting, the Japanese Institute of Disaster Mitigation for Urban Cultural Heritage of the Ritsumeikan University (R-DMUCH) has been acting as a catalyst for organizing an international research, training and information network in the field of cultural heritage risk management and disaster mitigation.

After this groundwork experience, the 3rd World Conference on Disaster Risk Reduction (WCDRR) in Tokyo and Sendai recommended an integrated approach for disaster risk management for different heritage types, movable and immovable as well as tangible and intangible, in order to create better disaster-resilient communities constituting, undoubtedly, a huge step forward for cultural heritage disaster risk reduction understanding.

Given the increasing occurrence of natural disasters in Myanmar, communities can play a crucial role in assisting the DOANM (Department of Archaeology, Museum and Library of Myanmar) for reducing risk as well as mounting efficient first responses for safeguarding built cultural heritage. Within this context, in Bagan a training sessions has recently been held organized jointly by the Department of Archaeology of Myanmar, UNESCO and ICCROM, which was targeted at paving the way for developing a strong partnership between various community-based organizations and government institutions engaged in first aid operations in Bagan, and at also employing volunteers.

In addition to the above, the newly prepared trainers have expressed their willingness to continue training volunteers with the active support of religious bodies, DOANM, UNESCO and ICCROM. To this end, they would like DOANM to appoint a focal person to liaise with the trained volunteers and NGO representatives. Furthermore, they have requested a short follow-up workshop to develop a common strategy for undertaking salvage and documentation at more temples and pagodas.

In India, international training on disaster risk reduction has been hosted since January 2017 in the Anni subdivision of Kullu district of Himachal Pradesh in northern India, as the part of the Community-Based Disaster Risk Reduction (CBDRR) project of the United Nations Development Programme (UNDP) and the Himachal Pradesh Government.

In Nicaragua and Chile, although these are very prone countries to disasters, as far as the first priority area of the Sendai Framework is concerned, there are not many organizations working on training and risk awareness or disaster risk reduction meetings. 
In Chile, the National Center for Conservation and Restoration (CNCR) Paper and Books Laboratory gives courses on the preservation of paper collections to personnel of libraries, archives and museums every year. People are trained on the topic of evacuation and drying of paper materials from flooding, as well as the recovery of damaged buildings. The main risks that Chilean heritage have faced through history are earthquakes, but they are also due to climate change such as flooding, mudslides and forest fires as well. So, training is focused on having in mind the kind of damage caused in these situations.

These efforts are not enough and open talks, civic talks, world cafès and multimedia platforms should be enhanced across the country and across South America as well, addressing also flooding and the other common sources of risk and damage.

In Italy and in the Balkans region, many training activities have been carried out in order to help a larger public to understand disaster risk reduction and disaster risk preparedness.

In the Balkans, Jovana Mijatovic, conservator and an attendant of the First Aid to Cultural Heritage in Times of Crisis course at ICCROM, realized several training programmes on behalf of the recently created 'Balkan Cultural Aid Response for Emergencies (B + CARE)' network. This organization is the result of a strong partnership between Cultural Heritage without Borders-Albania (CHwB) and the Urban Development Center-Belgrade (UDC)-Serbia, with young professionals from Albania, Bosnia and Herzegovina, Kosovo, Macedonia, Montenegro and Serbia. In all the training meetings she led, she tried to follow the overall methodology laid out by ICCROM. The scenarios and exercises were tailored to the specific types of incidents that were most likely to play out in the Balkans generally and in the context of the specific cities where the training was organized.

In Italy, in December 2016 the Workshop "Seismic Risk Prevention in Italy and Japan" in Rome was held at the House of Representatives. The training was attended by the president of the National Institute of Geophysics and Vulcanology (INGV). The event was organized by the Foudation Italy Japan, the Ministry of Foreign Affairs, and the Japanese Embassy. It was an opportunity for sharing where the two countries, famously characterized by high seismicity, put in place experiences and mutual knowledge in the prevention and management of calamitous events. Italian and Japanese teachers and experts could discuss the issues of conservative architecture, seismic architecture and the protection and restoration of cultural heritage. In conclusion, there was a debate on Japan's best practices that in recent years has developed advanced construction and alarm techniques.

\subsection{Initiatives to Strengthen Disaster risk Governance for Cultural Heritage in the Analysed Countries}

On the subject of the second priority area of the Sendai Framework, and more specifically risk assessments, two accurate mapping projects of Middle East regions' cultural heritage have been created:

- The Million Image Database by the Institute for Digital Archaeology (a collaboration between Harvard University, the University of Oxford, and Dubai Museum of the Future);

- The CyArk initiative for the digital recording of cultural heritage around the world.

Open talks, civic talks, world cafès and multimedia platforms are almost absent in the Middle East as well as in the other analysed countries, and employing more trained volunteers for emergency response should be enhanced, as well as actions focused on the involvement of private investors (also proceeding from foreign countries) in disaster risk management plans.

According to the necessary design of specific measures for disaster risk reduction in order to strengthen local governance, as stated in the second priority area of the Sendai Framework, the Japan Disaster Relief Team (JDR) is the national organization leader in the field of operating procedures for emergency response.

Moreover, the government launched in 2015 the Japanese White Paper on Disaster Management, one of the Japan's most noteworthy initiatives and comprehensive reports. Other countries can learn from Japan's example and adapt this model for their own needs. 
The White Paper on Disaster Management was first published in Japan in 1963 pursuant to the Disaster Countermeasures Basic Act. The 53rd edition was reported to the National Diet after cabinet approval on 19 June 2015. This year's white paper highlights the Third UN World Conference on Disaster Risk Reduction (WCDRR), held in Sendai in March of that year.

This groundwork document looks at the revisions made to disaster countermeasures based on the heavy snows in February 2016, the landslide in Hiroshima in August 2016, and the eruption of Mt. Ontake in September. It also provides information on the latest disaster risk reduction initiatives implemented by the national government, local governments, and community residents, and introduces a case study on an earthquake centered in northern Nagano Prefecture in which no casualties occurred thanks to mutual community support.

Based on the view that disaster counter measures are never "costs", but rather investments in the future, the Government of Japan is wholeheartedly committed to achieving safe and secure living. Therefore, they intend to proactively request that all citizens of Japan maintain a reasonable awareness of natural threats, be well prepared in advance for the hazards they face, refuse to react to false alarms, and take actions to protect themselves from disasters.

It is an important proactive approach to be held in high esteem as Japan holds a heritage of residential buildings made of wood or other natural materials worthy of note and encourages the use of active ecological tools to maintain both this type of construction (Figure 5) and the natural habitat, with which man has cooperated since ancient times, intervening in some areas to mitigate the risk of disasters.

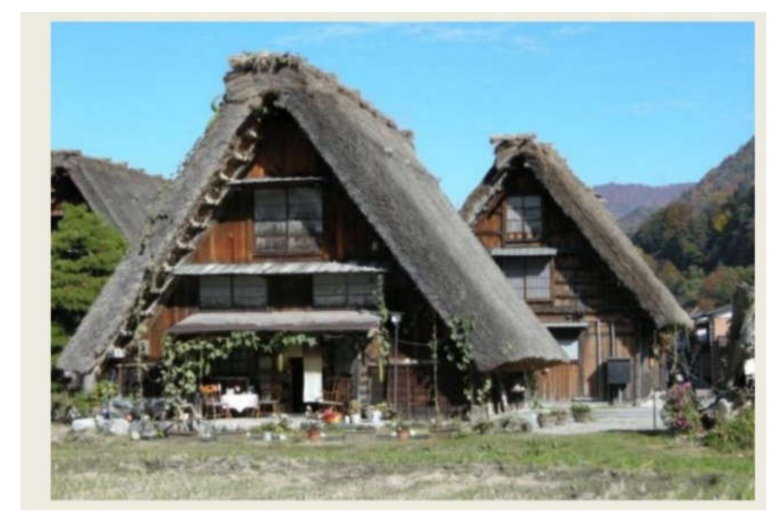

Figure 5. A Minka building, a traditional house in Japan, with roofs covered by straw and wooden structures. Photograph: Veronica Piacentini.

This relationship between man and environment to exploit spontaneous plants or terraces to convey waters or stem flooding is called Eco Design or Ecosystem Based Disaster Risk Reduction and has been included in the UN International Strategy for Disaster Risk Reduction (UNISDR) [28].

The country can rely not only on the White Paper on Disaster Management but also on the Law of the Disaster Relief Act. The purpose of the law is to provide essential emergency relief in the event of a disaster through the cooperation of local governments, NGOs, such as the Japanese Red Cross Society, and the general public, so as to protect disaster victims and maintain social order.

Italian Civil Protection has set up a deep collaboration with ICCROM through the Euromed Programme on Prevention, Preparedness and Response to Natural and Man-made Disasters, (PROMEDHE), a four-year recently accomplished initiative funded by the European Union, aimed at strengthening civil protection in the Mediterranean and Balkan countries, through the reinforcement of a civil protection culture based on prevention rather than response, and on inter-institutional dialogue at both national and local levels [29]. Italy is the coordinator of the PROMEDHE project, and has already developed strategies and preparedness measures to cope with cultural heritage safeguards in the case of disasters. 
Within the PROMEDHE framework three training courses have been carried out in Italy at Città di Castello (Umbria) from 2016 to 2018, providing ICCROM with a valuable opportunity to collaborate with civil protection and cultural heritage professionals from five different countries of the Euro-Mediterranean region. This also provided evidence on the need to protect cultural heritage and its integration into mainstream emergency response.

5.3. Strategies and Actions to Improve Financing of Disaster Risk Reduction, as Well as Response and Recovery in the Analysed Countries: Goals and Gaps

With respect to financing, the team project "Community Based Disaster Risk Reduction" of the UNDP, the State Government of Himachal Pradesh has no funds allocated for its work, and it is based only on community funding. Crowdfunding campaigns should be launched for this, as well as for the necessary works in the other countries of Asia.

Multimedia platforms or social events should be enhanced, both in India and in Latin America, but also in the other continents of the analysed countries, most specifically those focused on the subject of including private investors (also internationally located) in disaster risk management plans.

To create operating procedures within the fourth priority area of cultural heritage recovery and reconstruction, some professionals have recently worked hard in Syria and Iraq without adequate funds, as well as facing problems on the ground.

The ICOMOS permanent and operational working group on Syria has been monitoring this with the highest priority and intensifying contacts with other organisations, such as the DGAM and other universities, as well as involving them in research. Their activities also include establishing a database with the architectural and urban documentation of all the cultural heritage sites in both Syria and Iraq, starting with a 3D documentation of the old city of Damascus with the assistance of the American CyArk Foundation. On behalf of the annual general meeting of its members in November 2015, the board of ICOMOS Germany adopted a memorandum, 'For the Safeguarding and Preservation of the Cultural Sites in Syria', which, hopefully, could be the groundwork for a master plan.

Additionally, professionals who have attended the course 'First aid to Cultural Heritage in Times of Crisis', held since 2010 in Rome, Amsterdam, Washington and other cities within the framework of ICCROM's multi-partner and international programme on Disaster Risk Management, have been invited to submit proposals to carry out projects in their respective countries. For example, Sonia Ibrahim, an architect professor in the DGAM in Damascus, has recently prepared a damage assessment for historic building and sites in Syria, with third-year students at the Faculty of Architecture. She tried to make effective what she learned at the course, so they analysed every site and damaged building. They also want to release a book from the posters. In addition, they have been collaborating with the GORS (General Organization of Remote Sensing) in Syria to do some GIS (geographic information system) planning so that their work will be more accurate.

In Asia, although Japan is well organized in the case of disaster preparedness and response, specific protocols aimed at cultural heritage protection and recovery have not been designed. Advanced construction and alarm techniques have been developed, but a national and regional master plan specifically oriented to cultural heritage collections recovery is absent.

Myanmar and India also need specific protocols of intervention.

Nonetheless in India, the team project 'Community Based Disaster Risk Reduction' of the UNDP and State Government of Himachal Pradesh is running at local level (Anni Subdivision of Kullu district) with the involvement of the local community. As part of the team project, various teams are being created at a local level to work together with inhabitants within priority areas such as: rescue team ("Bachaav Dal"), first aid team ("Prathmik Upchaar Dal"), communication team ("Suchana Dal") etc. Another aspect of the team project is going to be to nominate people from the local community for the various teams, and to train specialized people to form the new aiders.

In Latin America, Nicaragua brings large experience on NGO collaboration and external financing with successful results. This aspect will be addressed below, because it deserves a special analysis 
to understand how to improve reconstruction and recovery plans in the aftermath of a disaster, especially in developing countries.

\subsection{Recovery Experiences in India, Nicaragua and Italy: Best Practices and Critical Points}

Concerning the fourth point of the Sendai Framework, in India and Nicaragua there have been some interesting reconstruction experiences that deserve to be analysed in more detail.

In India these were carried out after the Maharashtra earthquake of 1993, the cyclone that hit Orissa in 1999, and the Gujarat earthquake of 2001. India is a federal state characterized by a clear division of roles and responsibilities between the central government and state governments. Although the central government has an overall policy development and supportive role, the basic responsibility for rescue, relief, and rehabilitation lies with the state government. This factor combined with the highly unequal global attention and international humanitarian aid enjoyed by different types of disasters explains why reconstruction policies and practices within the framework of the aforementioned disasters varied significantly. Following the earthquake of 1993 that killed approximately 8000 people and fully destroyed about 27,000 houses, the government of Maharashtra announced a comprehensive housing reconstruction program that was the first of its kind in India. The program was primarily funded through a loan from the World Bank and grants from the Asian Development Bank and UNDP. In addition, several national and international NGOs joined efforts by rebuilding entire villages. Reconstruction in Maharashtra was mainly contractor-driven and entailed the resettlement of fully and severely affected villages [30].

The "super cyclone" hit Orissa in September 1999, killing more than 10,000 people and destroying approximately 800,000 houses. However, the disaster was not followed by a comprehensive governmental reconstruction program, and relatively few international agencies engaged in housing. People who lost their homes to the cyclone initially received a minor compensation grant. It is estimated that national and international NGOs took over the construction of only 5000 houses. Housing assistance provided by private agencies was not regulated by any specific policies, giving them the freedom to adopt any approach, house design, and building technology they deemed appropriate. While the 1999 Orissa cyclone raised awareness about the importance of disaster preparedness, including cyclone shelters, housing reconstruction gained less attention and accordingly was poorly documented. This may be attributed to the general tendency to pay more attention to housing reconstruction after earthquakes.

Uttar Pradesh, a province in northern India bordering the Himalayas, has more metropolitan cities than any other state in India. The absolute urban population of the state is 44.4 million, which constitutes $11.8 \%$ of the total urban population of India, the second-highest of any state. According to the 2011 census, there are 15 urban agglomerations with a population greater than 500,000 [31]. Three-quarters of the province is located in seismic zones III and IV with a moderate to severe risk of earthquake (the country is divided into five zones according to vulnerability to earthquakes, with areas in zone $\mathrm{V}$ having the highest risk). However, earthquake-resistant measures have not been incorporated in the contemporary design and construction of most buildings in the province, rendering them likely to collapse during earthquakes and thereby endangering the lives of the occupants. The UNDP Disaster Risk Management Program, and the Government of Uttar Pradesh decided to take steps to address the issue and improve the safety of school children in this region.

In Uttar Pradesh, the World Bank supported the construction of more than 6000 seismically safe school buildings that are part of the Education for All Project [32]. This is a practical, virtuous example that integration of disaster risk concerns during the design stage of the education facility can guarantee the construction of a building resilient to disasters. Education infrastructure is crucial for the development of human capital; it is impossible to achieve the Millennium Development Goals (MDG), when key infrastructures such as schools are lost or their use is interrupted due to disasters. Mechanisms to organize financing options for such an enormous task will have to be developed to "disaster-proof" the MDGs. To initiate the process, a workshop of the Uttar Pradesh Disaster Management Authority was convened at the initiative of the UNDP on 18 December 2005 to 
discuss the integration of earthquake-resistant measures in government buildings. Departments were requested to consider taking up this activity on a pilot scale during 2006-2007. The Elementary Education Department of the government of Uttar Pradesh responded by agreeing to integrate earthquake-resistant design for all new buildings to be constructed under Sarva Ahiksha Abhiyan (SSA: Education for All Project) in 2006-2007. The annual work plan under the SSA project involved 70 districts where the schools were to be constructed. This plan was under preparation and was to be finalized by April 2006. Consequently, to incorporate earthquake-resistant measures, the existing designs of the buildings had to be altered. New designs were prepared in consultation with seismic experts. This important operation could become a reference for new interventions on the traditional housing of the region, which can be considered built heritage.

To ensure adequate funding for the project, building-cost estimates were revised by the Public Works Department and Expenditure Finance Committee of the provincial government. Approval of the new drawings and estimates was also obtained from the National Seismic Advisor of the Ministry of Home Affairs of the government of India (the nodal ministry in the government of India for all activities related to disaster risk reduction).

This example of governmental initiative of Uttar Pradesh should be extended to the other regions at risk of India, as well as to other kinds of disaster emergencies in Asia or other developing countries and also to the protection of built cultural heritage, including the entire reconstruction process within a specific master plan and framework, and should consider also owner-driven approaches.

One of the challenges was to find adequate resources for the training and capacity building required to support the construction of earthquake-resistant school buildings. Government funds were available, but supplementary funding was welcome.

To train a sizeable mass of masons for the safe school project, the number of potential targets was large. With this challenge in mind, the people involved started seeking alternative sources of funds that could supplement the limited budget available from the government and the technical support of UNDP. A logical and simple option in such a situation is to tap the resources of private sector companies and corporate bodies. Companies have certain available substantial funds for market development, promotion and marketing. The funds can be spent on activities to attract consumers to the products of the company. The only proviso is that the funds have to be used for customer development. For example, for a program on the training of masons in safer construction techniques, the logical choices of companies are those involved in the manufacturing of construction material, for example, companies involved in the manufacture of steel and cement.

This public-private partnership ensured the conduct of more training sessions than would have been possible with the original government budget al.one. The initiative was based on a win-win relationship between the government and the private entities. The government gained by being able to organize more training events with the additional funding from the private organizations. The private organizations gained by increasing the publicity of their products. Both parties also gained from the goodwill of the other. The key lesson learned was that once a mutually beneficial model can be developed, a public-private partnership can be a success. This initiative also helped to build a partnership between the government and a private company, forging a healthy relationship in an area sometimes mired with suspicion and controversy.

Nonetheless, regarding the 'Build Back Better' issue in India, construction companies tend to build standard houses that do not respond to the specific requirements of the families for whom they are intended, although many agencies assume that employing professional construction companies is the quickest and most effective approach to rebuilding houses and re-establishing normality after a disaster. Currently, however, there is a growing awareness among experts and humanitarian agencies that this is not necessarily the case [33]. When construction materials and expertise are alien to the local context, target communities may find future repair and maintenance needs difficult. For this reason, specific and general frameworks for reconstruction are needed. 
Agencies' preference for one approach or the other is rarely based on research on outcomes and the impacts of different reconstruction experiences. Despite the substantive volume of financial resources invested in this sector, there is a paucity of independent research on the overall outcome and long-term impact of different housing reconstruction approaches.

There are a few countries that lend themselves well to a comparative analysis of different reconstruction approaches adopted within the framework of the same or comparable disaster contexts. India may be an exception, which has undergone several major disasters over the past 15 years that were followed by large-scale housing reconstruction programs and involved multiple national and international multilateral, governmental, and non-governmental agencies.

In January 2001, less than 2 years after the Orissa cyclone, the Indian state of Gujarat suffered one of the most severe earthquakes of the country's recorded history. Nearly 20,000 people lost their lives, and more than 1 million people were rendered homeless. Approximately 344,000 houses were fully destroyed and 888,000 were reported damaged. Immediately after the disaster, the government announced a reconstruction policy that was similar to that of Maharashtra. However, whereas contractor-driven reconstruction anti relocation was readily accepted 8 years earlier in Maharashtra, this was not the case in Gujarat, where the government policy met with stiff public resistance. This led the government of Gujarat to abandon its initial reconstruction policy and opt for an owner-driven reconstruction approach. This policy consisted in offering financial and technical assistance and subsidized construction materials to all those who preferred to undertake reconstruction on their own and who rejected relocation and full-scale "adoption" by an external agency. Given the option, $72 \%$ of the people opted for financial compensation to reconstruct their houses on their own [34]. Although many local NGOs respected people's preference for building their houses on their own, and hence assumed an enabling role (through the provision of training, the promotion of low-cost eco-friendly building technologies and some material support on top of the government compensation), most international agencies and private corporations manifested a clear preference for the adoption of full villages, contractor-driven reconstruction, and relocation.

In 2004, a multisite survey was conducted aiming to compare citizens' satisfaction with different reconstruction approaches. The research also entailed a technical validation of people's perception on issues related to the quality of construction. It was found that owner-driven reconstruction was highly successful and met the highest level of citizens' satisfaction [35]. These findings were consistent with those of a study commissioned by the UNDP (2004) indicating that Gujarat may represent perhaps one of the most successful experiences of post-disaster reconstruction.

This panorama allows better analysis of the processes and outcomes of reconstruction in Tamil Nadu following the Indian Ocean tsunami of 2004. For various reasons, these three Indian states pursued rather different reconstruction strategies [36].

The mainly government-led, contractor-driven reconstruction in Maharashtra was followed by an owner-driven reconstruction policy by the government of Gujarat. Despite the fact that the Indian Ocean tsunami of 2004 hit India when the negative outcomes of contractor-driven reconstruction in Maharashtra and the positive experience with owner-driven reconstruction in Gujarat were already well documented, the vast majority of the agencies involved in reconstruction in Tamil Nadu and its vernacular architecture opted for contractor-driven reconstruction [37].

Unfortunately, external agencies systematically ignored local knowledge and building capacities. Overfunding combined with a lack of cultural and environmental sensitivity led to massive demolition of reparable and even undamaged houses in many villages. This analysis leads to the urgent need to create a complete and specific framework for reconstruction, also based on the Gujarat experience.

In Nicaragua, more than 40,000 homes were destroyed after Hurricane Mitch in 1998, leaving approximately 368,000 people homeless. Housing is a complex and very fragile asset in this country. It is linked to livelihoods, security, resilience and health, as well as to aesthetics, identity, and cultural tangible and intangible heritage. There were clear differences in how the communities in Nicaragua were able to cope with and recover from Hurricane Mitch. 
Housing interventions were commonly seen by governments and major agencies as an opportunity to enhance the precarious pre-disaster housing conditions, thereby reducing the vulnerability of its residents. However, the impact of the reconstruction projects varied considerably between the communities. In one community, the political will and the vision of sustainable improvement were strong. Therefore, the affected people's housing situation could be improved in a sustainable fashion. In the other community, the reconstruction process was marked by a lack of local capacity to manage and administer the external aid in responding to local needs, and elite captures and even impeded housing assistance to the most vulnerable people. Based on a comparative analysis of these two Nicaraguan communities [38], it is arguable that local timely disaster response plays a decisive role with regards to the long-term success of housing reconstruction projects.

It is essential, therefore, that external interventions consider local practices, capacities and needs in order to enhance disaster recovery.

New actors, especially national and local NGOs, also became involved in the housing reconstruction process. All this challenged successful coordination. In fact, there was hardly any coordination among the various post-Mitch housing projects [38].

The qualitative and quantitative disparities in the housing projects planned by external donors were enormous, and the national government failed completely to balance these strong differences. New housing by far exceeded the actual losses in Posoltega, which received media attention due to the tragedy at the Casita volcano, where a landslide coming down the volcano's south flank killed more than 2000 people in the villages of El Porvenir and Rolando Rodriguez, whereas only 350 out of a planned 500 housing units in Ocotal could be rebuilt due to the lack of funds.

Ocotal's reconstruction (Figure 6) project helped to improve the housing situation of the affected people in a sustainable fashion, enabling 780 owners to repair and 214 to rebuild their homes in situ [39].

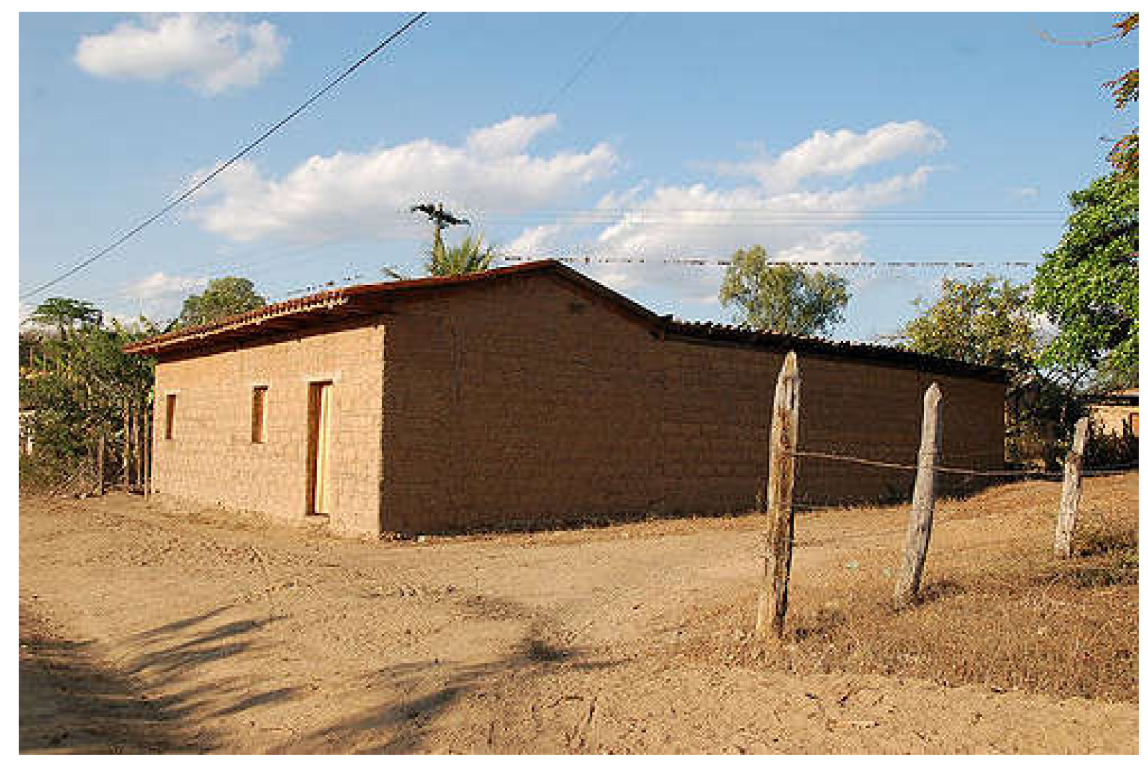

Figure 6. Adobe houses rebuilt following the local tradition in Ocotal, Nicaragua.

Moreover, a comprehensive new settlement comprising 230 houses was realized. The local authorities chose a culturally and socially sensitive reconstruction approach and searched for donors to finance the town's housing interventions. In the first phase, the reconstruction process was marked by transparency; it accorded well with the local building traditions, the housing design and settlement layout sufficiently met the residents' needs, and it focused on the creation of a new neighbourhood identity. The resettlement project proved to be successful, although having obtained a high occupancy rate and degree of residents' satisfaction, a complete change of local government and administration 
turned out to be problematic concerning the maintenance of transparency and the good quality of construction. Nevertheless, people's capacity to organize themselves was enhanced so that the committee of the inhabitants, for example, was successful in countering the formation of youth gangs in its neighbourhood.

San Dionisio's local authorities missed the chance to envision their own comprehensive reconstruction project, but rather accepted whatever assistance was offered regardless of whether such assistance responded to the local people's needs.

The housing interventions of the national government and of the multilateral agencies failed to respond to local needs, and this had negative implication with regard to people's vulnerability to natural disasters. The relocation undermined the rebuilding of livelihoods as the built settlements are at a considerable distance from their inhabitants' main sources of income and the plots are too small for small animal husbandry and family gardens. The settlements lack basic infrastructure (especially drinking water) and access to firewood and, therefore, the women's workload increased substantially. The quality of construction turned out to be very poor and the construction materials and techniques do not allow the people to perform the indicated repair works. As a result, many families moved back to their former homes in the risk zones and rebuilt them on their own. The occupancy rate of the new houses is low. The ability to jointly solve collective problems in the settlements is limited and the social vulnerability of the inhabitants is serious.

Local authorities' reconstruction plans in San Dionisio hardly responded to local needs, this case being somewhat similar to what occurred in New Orleans, USA, in the aftermath of Hurricane Katrina. The people-centered approach to design, proposed by the Sendai Framework and the UNISDR strategic frameworks, has not been largely applied to the recovery of the towns and territories affected by Hurricane Katrina. The press pointed out on that occasion that building new housing after a disaster is an opportunity for new business [40].

This kind of approach has not been strengthening local resilience nor traditions, built heritage as well as immaterial and intangible heritage. Protecting the local community should be, on the contrary, one of the first objectives of a recovery master plan which, to the present day, is totally absent even in some developed countries, as will be seen next in the case of Italy.

Since 1997, during the Umbria and Marche earthquakes, Italy has started to work on safeguarding and protecting movable and immovable cultural heritage in danger, by considering specific procedures and actions addressed to cultural assets and properties. These procedures have been improved and perfected in subsequent disasters, particularly during the 2009 Abruzzo earthquake, and during the 2016/2017 central Italy earthquake. Starting from 2005, Italian Civil Protection has introduced the safeguard of cultural heritage in the scenario of both national and EU-funded field exercises-i.e., EUROSOT (2005), TEREX (2010), MESIMEX (2006) and TWIST (2013). Such experiences helped improving both procedures and expertise for the safeguarding of cultural heritage during disasters. These procedures were shared during the international workshop held on 26 May and 28 August 2017, in Città di Castello (Umbria region in Italy), and built upon its large experience, where the Italian Department of Civil Protection invited ICCROM to collaborate, in order to facilitate a specialized training course on the protection of cultural heritage within the PROMEDHE framework.

At the fourth session of the Global Platform, Franco Gabrielli, chief of Italian Civil Protection in that moment, pointed out for the first time the basic guidelines of the promoted national procedures.

The Global Platform is a biennial forum for information exchange, the discussion of latest developments, knowledge and partnership-building across sectors, with the goal of improving implementation of disaster risk reduction. Its core function is to enable governments, NGOs, scientists, practitioners, and UN organizations to share experience and formulate strategic guidance.

Gabrielli declared that Italian Civil Protection was firmly convinced that the then existing Framework for Action could be improved through the inclusion of more practical targets and indicators in order to facilitate a more complete assessment of the results achieved, for example, in terms of transparency, education and information to the population. 
He made the public observe that there is no "one size fits all" model that one can rely on in terms of disaster risk reduction governance, since every country would adopt the most appropriate according to its own priorities and needs.

Nevertheless, effective integration of disaster risk reduction into national and local policies and plans requires a clear identification of roles and responsibilities. Therefore, more efforts should be made to promote an exchange of lessons learnt and good practices. In this regard, for the sake of a more effective implementation of disaster risk reduction worldwide, the Italian National Civil Protection Department truly encourages the reinforcement of UNISDR capabilities and resources.

Gabrielli also declared that community resilience stands at the highest rankings of the Italian Civil Protection agenda. Their commitment to promote deeper knowledge and to improve capabilities at local level, as well as to ensure that the institutional and legal framework for disaster risk reduction, is clear and consistent. It is also extremely important to further progress towards a more effective involvement of the private sector in disaster risk reduction. This has already proved to be a successful approach in relation to the recent earthquake that affected northern Italy in 2012.

On the other hand, specific protocols, social tools and multimedia platforms should be enhanced, both in Italy and in the Balkans, in order to strengthen risk prevention, funding and preparedness as well as to reduce cultural heritage vulnerability. According to the recent press news and the surveys of the volunteers of the association of RESEDA Onlus in the region of Amatrice, with reference to responding to affected people needs, the institutional means and intentions are still inadequate (Figure 7).

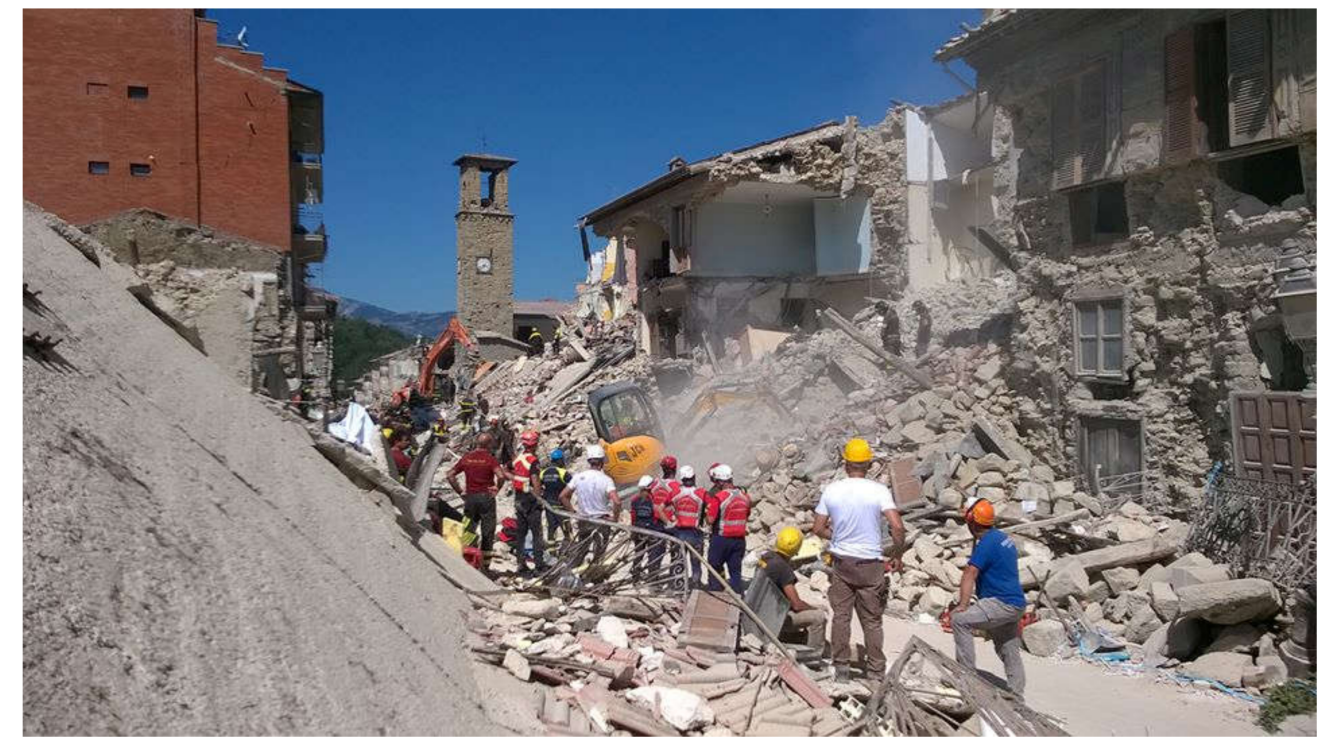

Figure 7. Salvage operation after the earthquake of August 2016, which destroyed the historic center of Amatrice. After one year, rubble is still on the streets. Photograph: Roberto Salustri.

After the recent earthquake in central Italy (2016), the reconstruction national legal framework has been officially activated, six months after the disaster; but after one year and a half housing conditions and local services are still precarious, together with the lack of real reconstruction work.

Territorial policies focused on seismic retrofitting of historic and recent buildings to prevent disasters are urgent. According to the The Italian General Confederation of Labour (CGIL) syndicate of Corso d'Italia, "the experience of the last few months and the last few years shows that when the normal maintenance of the territory is discharged and when the governance ignores the logic of risk prevention, the consequences on people and things become dramatic" [41]. The note also states that: "public financing on emergency interventions is also greater and less programmable than what can be allocated for a multiannual maintenance and prevention program. This logic seemed to be included in 
the 'Casa Italia' program, the traces of which have actually disappeared, a sign that it was not such a solid commitment as the Government had presented it".

CGIL denounces that: "The earthquake and earthquake risk have been well-known for years, but nothing has been done to prevent and mitigate the adverse effects on the communities and economies of the affected territories".

Although the Earthquake Decree (Dlgs. 189/2016) was issued, subsequent implementation measures and the Memorandum of Understanding between the Extraordinary Commissioner for Reconstruction Vasco Errani and the network of technical professionals were needed to develop the criteria governing professional fees and reconstruction work, in terms of quality, quantity and expertise. A series of bureaucratic improvements in urban planning in historic centers have allowed the speeding up of seismic adaptation works, as is the case with D.P.R. 9 July 2010, No. 139 published in G.U. Of 26 August 2010, No. 199, updated after the seismic event (D.P.N. 311/2017-Simplified Landscape Authorization for Small Interventions).

The text (DL 189/2016), published in the official journal, confirms the measures announced by the government, i.e., facilities for the reconstruction of first and second homes and business aid. However, there are no practical mechanisms to obtain funding and start works, although tight deadlines are foreseen for their adoption.

The first put into force has been the decree with the operational provisions for immediate execution. These are works that can be carried out on properties with slight damage, i.e., those with the Feasibility and Damage in the Seismic Emergency (AeDES) capability "B". The AeDES system is a tool based on evaluation forms to realize the post-emergency monitoring of buildings [42]. Capability " $B$ " means: "Building temporarily unusable (in whole or in part) but accessible by emergency measures" [43]. The decree had been validated by the extraordinary commissioner for reconstruction, Vasco Errani, by 3 November 2016 ( 15 days after the entry into force of the earthquake decree). If a previous AeDES inspection states the building's unavailability, municipalities must require further revisions through the procedures indicated in the circular of 28 December 2016.

\section{Overview of Appropriate Measures and Gaps in Cultural Heritage Protection from Disaster Risk in the Analysed Countries}

As far as the Middle East is concerned, to date the uncertain collaboration between Boston University and Mosul University presented at the conference "The Future of the Past: From Amphipolis To Mosul" in 2015 by Allison Cuneo, and the weak participation of local stakeholders in the management and preservation of urban and rural cultural sites in Turkey presented by Emily C. Arauz at the same event, pointed out that there have not been enough international partnerships yet to contrast the huge loss of cultural heritage in these countries.

Another problem is the restricted access to the results of archaeological research, which impedes attempts to protect the Middle East's built cultural heritage, as it reinforces the public perception of academia as an elitist, secretive, bureaucratic and dysfunctional ivory tower, while interacting with local communities regarding the value of their cultural treasures and treating them as equal partners should be the first step towards a sustainable, constructive relationship that stands to benefit the preservation and protection of archaeological sites in these regions.

Many of those who work and conduct research in the eastern Mediterranean return at the end of an excavation campaign or survey season to their respective institutions without developing a strong bond with their local counterparts who are, after all, responsible for the well-being of these sites.

Overall, public outreach and community engagement are very urgent topics in the Middle East region as well as coordinating a website platform that could enhance local protocols and master plans.

In Myanmar, the State Peace and Development Council (SPDC) did not operate in collaboration with foreign countries and organizations. Even within its own country, the SPDC took measures to ensure its solidity as the ruling power along with its leader, General Than Shwe. The SPDC maintains strong opposition to outside influences, which might be driven by an exaggerated fear of external 
interference in Myanmar, including a possible invasion by the United States and a deep-seated distrust of the National League for Democracy (NLD), Aung San Suu Kyi, and all non-Burmes groups [44].

The isolationist policies of the Myanmar government prevent most forms of external assistance in times of catastrophe. Therefore, the biggest challenge for the international community to send aid to Myanmar is its government. The international community should restructure its approach to donating aid to Myanmar. Along with keeping its motives neutral and truly humanitarian, it should take the necessary steps to ensure a more effective means to encourage a social change. For instance, Cooperation with ASEAN (Association of South-east Asian Nations) members and other Asian nations would relieve some political pressure against Myanmar, allowing its government to be less defensive to foreign powers [45].

In the other analysed countries of Asia, the lack of adequate funds and policies creates diverse operative solutions, which on just a few occasions has led to a satisfactory recovery of cultural heritage elements and environmental qualities.

In Chile, although the Risk Management Committee of the National Center for Conservation and Restoration (CNCR) is working with the intention of emphasizing emergency and disaster preparedness, response and risk reduction, there has not been any formal activity yet and it is difficult to coordinate the different actors as they all have many different functions and tasks to fulfil. A consistent network could be created between conservators from CNCR with contacts in ICOMOS or ICCROM national committees, together with someone else from the National Council of Culture and Arts, and someone from the National Council of Monuments.

In Nicaragua, housing the reconstruction process was characterized by a lack of national coordination of efforts. Both the capacity and the political will of the national government to actively design, plan, and steer housing reconstruction according to local traditional construction were lacking. The national government did not successfully contribute to an allocation of aid according to actual needs. Clear national criteria of determining who had been affected, to what degree and, therefore, who might be eligible for assistance were missing, while the local and participative disaster response played a decisive role with regard to the long-term success of housing reconstruction projects. A national and regional master plan to "Build Back Better" which pays special attention to cultural heritage recovery with a bottom-up coordinated and participated approach is absent, as well as in the other analysed countries.

In western countries very prone to natural disasters like Italy, a national unique operating plan for disaster risk reduction is absent. The 'Casa Italia' plan, presented by the previous government guided by Matteo Renzi, foresaw prevention and disaster risk management procedures in terms of coordinated interventions. The biggest critical aspect of actual Italian disaster risk reduction management is the lack of prevention, reducing coordinated efforts just to response. This is a gap common to the entire international scenario and affects all the member states of the UN that signed the Sendai Framework. This is the reason why it would be highly recommendable that, within this groundwork, national master plans connected with regional operating procedures could be enhanced.

\section{Conclusions}

Is well known nowadays that increasing territorial vulnerability is linked to cultural heritage protection, which is in turn related to local identity and social resilience. An effective national, regional, and local participative disaster response plays a decisive role for the long-term success of historical buildings and housing reconstruction, as well as cultural heritage collection recovery. But this process must be guided through specific frameworks or protocols. In order to achieve this outcome, precise assessments, remote-sensing monitoring and validated standard operating procedures are fundamental. National policies should follow the priority areas of intervention given by the Sendai Framework, as they have been universally recognized as a primary concern for disaster risk reduction worldwide. Nonetheless, these general guidelines must be implemented and made operative locally. It is recommendable that any international intervention considers local practices, capacities, and needs 
in order to enhance disaster recovery. Local authorities obviously have an advantage in knowing the needs and preferences of their communities, so they have been empowered through capacity-building actions. The most decisive local factors for the long-term outcome of the post-disaster recovery interventions are political will and the vision of the local authorities to enhance their communities' resilience, their efforts, to respond to people's needs and preferences, and their capacity to properly manage the reconstruction projects. External interventions should support local authorities to reach a position enabling them to adequately respond to people's needs and to support the latter's own efforts, even by the use of new technologies. Such support, however, should only be provided if recovery projects can be shown to be sound and well thought through, and the process of their implementation is marked by transparency, within a global framework or validated master plan.

Overall, regarding the four priority areas of the Sendai Framework and the actual risk management policies and actions led by the countries analysed in the present report, their gaps and possible solutions can be described as follows:

1. Training and action oriented to education (cultural heritage protection and meaning, and so on), moreover those regarding communities' involvement, are starting to be undertaken, but are still scarce, and a distance between community-based organizations and policies led by regional and national governments is evident. These organizations (associations, universities, schools, etc.) should be more connected to local authorities through agreements or contracts.

2. First aid networks and policies oriented to cultural heritage protection from man-made and natural disasters have recently been created, but must be strengthened and connected with new partnerships, together with finding new private funds. Protocols and peer-to-peer urbanism platforms should also be created, in order to use ICT technologies, early-warning systems, and remote sensing for monitoring, risk assessment and traditional housing recovery.

3. Solutions must be found to the lack of funding and national frameworks oriented to owner-driven policies of reconstruction, e.g., crowdfunding platforms and social participation activities to territorial management and urban regeneration. Risk impact assessments and risk sensitive investments must be strengthened. Studies on these topics at a university level have noty been encouraged enough and they should be disseminated across countries. The challenge is to ensure the inclusion of analysis based on hazard and vulnerability assessments in all development investments.

4. Effective master plans at international, national and regional levels should to be developed, based on local communities' participation and an owner-driven approach to reconstruction, in order to protect the traditional environment while interchanging and reviving local know-how and best practices.

Acknowledgments: To Aparna Tandon, Project Manager at ICCROM, Desaster Risk Department; to Mario Cerasoli, Professor of Urban Planning at the Roma Tre University and supervisor of my post-doctoral research funded by the Marie Sklodowska-Curie Programme.

Conflicts of Interest: The authors declare no conflicts of interest.

\section{References}

1. Nuttall, N. Global Response to Climate Change Keeps Door Open to 2 Degree C Temperature Limit; UNFCCC Press Office: Bonn, Germany, 2015.

2. Sudhiraa, H.S.; Ramachandraa, T.V.; Jagadishb, K.S. Urban sprawl: Metrics, dynamics and modelling using GIS. Int. J. Appl. Earth Obs. Geoinf. 2004, 5, 29-39. Available online: https:/ /www.sciencedirect.com/science/ article/pii/S0303243403000230 (accessed on 12 January 2017). [CrossRef]

3. Piacentini, V. Strategie di retrofit energetico di edifici storici dell'area metropolitana di Roma. In Libro degli Atti del $9^{\circ}$ Congresso Città e Territorio Virtuale-Città Memoria Gente. Roma, 2-4 Ottobre 2013; Cerasoli, M., Ed.; Roma TrEpress, Università Roma Tre: Roma, Italy, 2015. 
4. Andreassi, F. La città evento: Nuova società e nuovi spazi pubblici. Il caso dell'Aquila. The Event City: New Society and New Public Spaces. The Case of L'Aquila. In Society, Integration, Education; Personality Socialization Research Institute and Department of Civil Engineering and Architecture, University of Udine: Udine, Italy, 2013; Volume 3, pp. 181-188.

5. Salat, S. Cities and Forms: On Sustainable Urbanism; Hermann CTBS: Paris, France, 2011.

6. ICOMOS. The Valletta Principles for the Safeguarding and Management of Historic Cities, Towns and Urban Areas, 2011. Adopted by the 17th ICOMOS General Assembly. Available online: https:/ /www.icomos.org/ Paris2011/GA2011_CIVVIH_text_EN_FR_final_20120110.pdf (accessed on 23 February 2018).

7. Cerasoli, M.; Rizzo, B. Il futuro tecnologico dei centri storici. In Libro degli Atti del $9^{\circ}$ Congresso Città e Territorio Virtuale-Città Memoria Gente. Roma, 2-4 Ottobre 2013; Cerasoli, M., Ed.; Roma TrEpress, Università Roma Tre: Roma, Italy, 2015.

8. UNESCO. Strategy for Reinforcing UNESCO's Action for the Protection of Culture and the Promotion of Cultural Pluralism in the Event of Armed Conflict, Paris, 2015. Available online: https:/ / en.unesco.org/ system/files/unesco_clt_strategy_en.pdf (accessed on 1 January 2018).

9. Vaher, L. Risk Management and Cultural Heritage. E-Conserv. J. 2015, 3. [CrossRef]

10. Gullì, L.; Talò, F. Cinquant'anni di esperienze nella gestione dei centri storici in un caso esemplare/Fifty years of experience in the management of city centres: An exemplary case. Cap. Cult. Stud. Value Cult. Heritage 2012, 5, 41-61. [CrossRef]

11. Iperurbano. Piedi per Terra e Testa nel Cloud. Available online: www.urbanexperience.it/ (accessed on 21 November 2017).

12. Transition Network. org. A Movement of Communities Coming Together to Reimagine and Rebuild Our WORLD. Available online: https:/ / transitionnetwork.org/ (accessed on 10 December 2017).

13. Adell, N.; Bendix, R.F.; Bortolotto, C. Between Imagined Communities of Practice: Participation, Territory and the Making of Heritage; Universitätsverlag Göttingen: Göttingen, Germany, 2015; ISBN 9783863952051. ISSN 2190-8672. Available online: http:/ / biblio.iccrom.org/cgi-bin/koha/opac-detail.pl?biblionumber= 120378 (accessed on 21 November 2017).

14. Iperurbano. Rigenerazione Urbana Altamura. Available online: http:/ / www.iperurbano.it/ (accessed on 1 December 2017).

15. CORDIS. Servizio Comunitario di Informazione in Materia di Ricerca e Sviluppo. Available online: http: / / cordis.europa.eu/project/rcn/208560_it.html (accessed on 7 July 2017).

16. Europeansmartcities. Available online: http://www.smart-cities.eu/ (accessed on 23 February 2018).

17. Iperbole Rete Civica. Available online: http:/ / comunita.comune.bologna.it/node (accessed on 21 November 2017).

18. Karaca, F. An AHP-based indoor Air Pollution Risk Index Method for cultural heritage collections. J. Cult. Herit. 2015, 16, 352-360. [CrossRef]

19. Appendino, F. A comparative approach for sustainability assessment in historic urban context. In Proceedings of the Heritage 2016 5th International Conference on Heritage and Sustainable Development, Lisbon, Portugal, 12-15 July 2016; Available online: http:/ / heritage.greenlines-institute.org/ (accessed on 22 December 2017).

20. Wang, J.-J. Flood risk maps to cultural heritage: Measures and process. J. Cult. Herit. 2015, 16, $210-220$. [CrossRef]

21. Novelli, V.; D'Ayala, D.; Makhloufi, N.; Benouar, D.; Zekagh, A. A procedure for the identification of the seismic vulnerability at territorial scale. Application to the Casbah of Algiers. Bull. Earthq. Eng. 2015, 13, 177-202. [CrossRef]

22. Final Report Summary-FIRESENSE (Fire Detection and Management through a Multi-Sensor Network for the Protection of Cultural Heritage Areas from the Risk of Fire and Extreme Weather Conditions). CORDIS, 2013. Available online: http:/ / cordis.europa.eu/result/rcn/143051_it.html (accessed on 31 November 2017).

23. International Council on Monuments and Sites (ICOMOS). Guidance on Post Trauma Recovery and Reconstruction for World Heritage Cultural Properties; ICOMOS: Paris, France, 2017.

24. Shondell Miller, D.; David Rivera, J. Community Disaster Recovery and Resiliency. Exploring Global Opportunities and Challenges; CRC Press: London, UK; New York, NY, USA, 2010.

25. Davidson, C.H.; Johnson, C.; Lizarralde, G.; Dikrnen, N.; Sliwinski, A. Truth and myths about community participation in post-disaster housing projects. Habitat Int. 2007, 31, 100-115. [CrossRef]

26. International Council on Monuments and Sites (ICOMOS). ICOMOS World Report 2011-2013 on Monuments and Sites in Danger (Heritage at Risk); ICOMOS: Paris, France, 2013; Volume 146, p. 9. 
27. Hecimovic, A. Devastation in Yemen: Historic District of Sana'a Before and After-In Pictures. The Guardian, 12 June 2015. Available online: https:/ / www.theguardian.com/world/gallery/2015/jun/12/old-town-ofsanaa-after-airstrikes-and-before-in-pictures (accessed on 13 November 2017).

28. Renaud, F. (UNU-EHS. Institute for Environment and Human Security) What Is Next for Ecosystem-Based Disaster Risk Reduction and Climate Change Adaptation? ICCG (International Center for Climate Governance) Webinar Series on Disaster Risk Reduction. 28 April 2017. Available online: http:/ /www. iccgov.org/wp-content/uploads/2017/04/Webinar_Renaud_ICCG.pdf (accessed on 21 November 2017).

29. Promedhe. Protecting Mediterranean Cultural Heritage During Disasters. Available online: http:/ / www. promedhe.eu/context/ (accessed on 21 January 2018).

30. Jigyasu, R. From 'Natural' to 'Cultural' Disaster. Consequences of Post-FA Earthquake Rehabilitation Process on Cultural Heritage in Marathwada Region, India. Communication presented at the International Conference on Seismic Performance of Traditional Buildings, Istanbul, Turkey, 2001. Available online: http:/ / www.icomos.org/iiwc/seismicijigyasu,pd1 (accessed on 30 August 2017).

31. Office of the Registrar General \& Census Commissioner, India. Census of India 2011: Provisional Population Totals Paper 1 of 2011, Uttar Pradesh Series 10; Directorate of Census Operations, Uttar Pradesh: Uttar Pradesh, India, 2011.

32. Singh, S.; Kumar, A. Politics and Public Policies: Politics of Human Development in Uttar Pradesh, India; Working Paper 287; Institute for Social and Economic Change: Bangalore, India, 2012; pp. 1-14.

33. Barakat, S. Housing Reconstruction after Conflict and Disaster; Paper No. 43; Humanitarian Practice Network: London, UK, 2003.

34. Jha, A.K.; Barenstein, J.D.; Phelps, P.M.; Pittet, D.; Sena, S. Safer Homes, Stronger Communities. A Handbook for Reconstructing after Natural Disasters; Collection World Bank Training: Washington, DC, USA, 2010; pp. 103-104.

35. Duyne Barenstein, J. Housing Reconstruction in Post-Earthquake Gujarat: A Comparative Analysis; Paper No. 54; Humanitarian Practice Network: London, UK, 2006.

36. Shondell Miller, D.; David Rivera, J. Community Disaster Recovery and Resiliency. Exploring Global Opportunities and Challenges; CRC Press: London, UK; New York, NY, USA, 2010; p. 346.

37. Duyne Barenstein, J. The socio-cultural context of post-disaster housing reconstruction: The case of tsunami-hit coastal Tamil Nadu. Presented at the Annual Swiss Solidarity Conference, Bern, Switzerland, 26 January 2006.

38. Leemann, E. Housing reconstruction in Post-Mitch Nicaragua: Two Case Studies from the Communities of San Dionisio and Ocotal. In Community Disaster Recovery and Resiliency. Exploring Global Opportunities and Challenges; Shondell Miller, D., David Rivera, J., Eds.; CRC Press: London, UK; New York, NY, USA, 2010; pp. 319-342.

39. Duyne Barenstein, J.E.; Leemann, E. Post-Disaster Reconstruction and Change: Communities' Perspectives; CRC Press: London, UK; New York, NY, USA, 2012.

40. The Long Read. Naomi Klein: How Power Profits from Disaster. Available online: https:/ www.theguardian. com/us-news / 2017/jul/06/naomi-klein-how-power-profits-from-disaster (accessed on 22 June 2017).

41. Terremoto: Cgil, Ripartire dal lavoro per fronteggiare L'emergenza. Available online: http://www. ildiariodellavoro.it/adon.pl?act=doc\&doc=62726\#.WaVVeWeG_0w (accessed on 12 July 2017).

42. Manuale per la Compilazione Della Scheda di $1^{\circ}$ Livello di Rilevamento Danno, Pronto Intervento e Agibilità per Edifici Ordinari Nell'emergenza Post-Sismica (AeDES). Available online: http:/ / www.protezionecivile. gov.it/resources/cms/documents/Manuale_AEDES.pdf (accessed on 22 February 2018).

43. Eventi Sismici Centro Italia 2016: Tutte le Indicazioni su Sopralluoghi, Verifiche di Agibilità e Interventi. Available online: http:/ / areaformazione.legislazionetecnica.it/articolo/1339/eventi-sismici-centro-italia2016-tutte-le-indicazioni-su-sopralluoghi-verifiche-di (accessed on 4 January 2018).

44. Bowman, V. The political situation in Myanmar. In Myanmar: The State, Community, and the Environment; Skidmore, M., Wilson, T., Eds.; Asia Pacific Press: Abu Dhabi, United Arab Emirates, 2007.

45. Shondell Miller, D.; David Rivera, J. Community Disaster Recovery and Resiliency. Exploring Global Opportunities and Challenges; CRC Press: London, UK; New York, NY, USA, 2010; p. 266.

(C) 2018 by the author. Licensee MDPI, Basel, Switzerland. This article is an open access article distributed under the terms and conditions of the Creative Commons Attribution (CC BY) license (http:/ / creativecommons.org/licenses/by/4.0/). 